\title{
Reactive Attitudes, Disdain and the Second-Person Standpoint ${ }^{1}$
}

\begin{abstract}
Disdain and contempt have often been taken to be vicious attitudes. This view has been further defended by Stephen Darwall in his ambitious and elaborate secondpersonal account of morality. In The Second-Person Standpoint, Darwall argues that disdain is problematic to the extent that it fails to recognize the authority and moral freedom of its object. In this paper, I will develop two answers to Darwall's claims about disdain. First, I will argue that, if we take Darwall's account to be ultimately grounded on what hypothetical members of the moral community would do, it would be difficult to argue that anything said at this level would justify an evaluation of what actual individuals should do. Second, even if we granted that the Second-Personal Standpoint could have such normative implications, I will argue that disdain, as a moralised attitude towards others who fail to behave morally, can not only be justified but can also be shown to presuppose the moral freedom of the wrongdoer. Finally, I will introduce a distinction between normative and empirical expectation to further clarify this point.
\end{abstract}

\section{Introduction}

In this paper, I will argue that, contrary to what Darwall has suggested, the Second-Person Standpoint cannot offer theoretical support for the view that we should not feel disdain and contempt towards wrongdoers. On the contrary, I will argue that it is not necessarily morally problematic to disengage from feeling resentment and anger towards those individuals who are prone to commit wrongdoings, and that feeling disdain or contempt, both attitudes of disengagement, therefore need not be morally problematic.

I will start by giving a brief description of the general account defended by Darwall in The Second-Person Standpoint (henceforth SPS). I will discuss in particular the role of the reactive attitudes in this account and their relationship to other crucial concepts in the SPS, such as second-personal competence, second-personal reasons and moral obligation. I will then examine the claim made by Strawson and endorsed by Darwall that the reactive attitudes constitute a form of demand for respect.

If reactive attitudes issue a demand, giving up on this demand by experiencing disdain could be problematic in various ways. I will discuss three ways in which experiencing disdain or contempt can be said to be problematic in this regard. First, it could imply that the victim gives up, so to speak, on having her demand be answered and this could indicate lack of self-respect. Second, failing to experience the reactive attitudes and experiencing disdain instead, might suggest that no moral obligation has been violated. Third, experiencing disdain could indicate lack of respect towards the wrongdoer. Darwall himself endorses this last view. In some passages of the SPS, he describes disdain towards the wrongdoer as failing to show respect to the wrongdoer as person.

In this paper, I will counter these views by defending the admittedly modest claim that contempt or disdain is not necessarily morally problematic. For this purpose, I will develop two arguments. To begin with, I will point to a general ambivalence in the SPS between an account rooted in the actual experiences of individuals and an argument about what dispositions ideal members of the moral community would have. If reactive attitudes are understood to be a form of demand for respect, as Darwall argues, then it matters a great deal

\footnotetext{
${ }^{1}$ Work on this paper was supported by funding from the European Research Council and the Research Council of Norway.
} 
whether this demand is formulated when individuals are actually experiencing the reactive attitudes or whether this demand exists in virtue of the disposition of ideal members of the moral community. I will argue that ultimately the argument as presented by Darwall is best understood as concerned with the dispositions of ideal members of the moral community towards the reactive attitudes. To the extent that this is the case, if individuals fail to experience the reactive attitudes and experience instead an attitude of disengagement, such as disdain or contempt, this doesn't undermine the fact that a moral obligation has been violated as only the disposition of ideal members ground moral obligation. The argument presented in this section thus seems to reject only one possible ground for taking disdain and contempt to be morally disvaluable. However, I point out that this argument would also undermine the validity of the two remaining arguments mentioned. This is because the ideal character of Darwall's account ends up blocking it from having any normative implications. But, given that Darwall could still argue that we ought nevertheless to strive to emulate the dispositions that hypothetical members of the moral community would have, I will explore another ground to deny the claim explicitly held by Darwall, that is, the claim that experiencing disdain might fail to recognize the respect owed to the wrongdoer as a morally free agent. For that purpose I will draw on the distinction between recognition and appraisal respect introduced by Darwall himself in an earlier work in order to show that feeling disdain towards a wrong-doer also presupposes that the wrongdoer belongs to our moral community. Moreover, I will introduce a distinction between empirical and normative expectation in order to argue that although stopping to expect better from particular agents at a normative level might be problematic, stopping to expect better at an empirical level is in fact often more appropriate. And I will claim that disdain requires only the latter. The argument concludes thus that disdain is not necessarily disvaluable or morally inappropriate.

\section{Darwall's Second- Person Standpoint: Morality as Equal Accountability}

Let me start by giving a brief sketch of the view developed by Darwall in The Second-Person Standpoint. Darwall describes the second-person standpoint as the "perspective you and I take up when we make and acknowledge claims on one another's conduct and will" (Darwall, 2006, 3). What this perspective is getting at ultimately is a conception of morality as a form of equal accountability to each other. This conception of morality as a form of equal accountability emerges from a circle of different concepts all linked together (as Darwall himself describes it): moral obligation, second-personal reason, second-personal competence and the authority to make demands on others.

On Darwall's account, the concept of moral obligation can only be understood from a second-personal perspective, that is, from the perspective of what you can demand from me and what I am accountable to you for. Moreover, I can only be morally obligated to do what there is a second-personal reason for me to do. A second-personal reason is a reason that depends conceptually on the victim having authority to make claims or demands. Second-personal reasons also imply an individual being addressed by them. Only secondpersonal reason can ground claims of moral obligation and thus rights. This being said, Darwall recognises the existence and relevance of agent-neutral reasons: the fact that if I do something I might cause pain to another being might still have a role in determining what to do. However, on Darwall's view, this being can only have a right not to suffer pain caused by me, if it has the authority to make claims or demands from me, that is, if there are second-personal reasons for me not to cause pain to it. Agent-neutral reasons, unlike second-personal reasons, are not conceptually connected to what we are morally obligated to do. And beneficial consequences pointed to by agent-neutral reasons can't ground any right.

So now it becomes pertinent to wonder what gives us this authority to make claims on others. If secondpersonal reasons depend on the victim's authority to make claims, what underlies the authority to make claims? Darwall answers this question by pointing to second-personal competence. According to him, second-personal competence makes us subject to moral obligation and also reciprocally gives us the authority to make claims and demands of one another as members of the moral community (Darwall 2006, 29). It is "the moral competence requisite for (equal) membership in the moral community" (Darwall, 2006, 75). 
But we might now wonder: what then grounds second-personal competence? What grounds second-personal competence is the ability to comply with norms (Darwall, 2006, 242). This compliance with norms should be done for the right reasons, that is, because the agent recognises the authority of the potential victims of her wrong-doing to make claims on her. Described in this way, second-personal competence is thus connected to autonomy. Darwall argues indeed that persons can have second-personal competence "only if we can assume autonomy and some form of moral reasoning like the Categorical Imperative." And in virtue of having second-personal competence, one attracts certain privileges: one can claim "respect for persons" and be acknowledged as free and equal (Darwall, 2006, 127).

However, unlike the Categorical Imperative, second-personal competence doesn't merely require a detached form of moral reasoning. This moral reasoning should be accompanied by the appropriate emotional attitude towards other agents. Darwall takes deficit in empathy to be deficit in second-personal competence (Darwall, $2006,75,25 \mathrm{f}$ ). Therefore, although high functioning autists can follow certain norms, they don't acknowledge second-personal authority and can't understand the basis for the principles of moral obligations that they are following. Autistic individuals, along with psychopaths, lack second-personal competence. However, once someone has second-personal competence, the degree to which this person has second-personal competence is irrelevant as it is a range property (Darwall, 2006, 75). ${ }^{2}$

To sum up, according to Darwall, in order to understand what is going on in moral accountability, we need to consider a "circle" of mutually involving concepts, which presuppose the second-person standpoint and can't be accessed from outside it. These concepts include the authority to make a claim or demand, the authoritative claim or demand itself, the second-personal reason for complying and the accountability for complying. I can only have the authority to demand that someone refrains from wronging me, if my demand is legitimate, if there is a second-personal reason for this other person to refrain from wronging me and if they are accountable to me for this wrongdoing. Moral accountability is thus irreducibly second-personal. (Darwall, 2010, 217-218).

\section{The Role of the Reactive Attitudes in the Second-Person Standpoint}

As mentioned above, Darwall argues that the concept of moral obligation should be understood from a second-personal perspective, that is, from the perspective of what you can demand from me. More specifically, what constitutes a moral obligation for me is what, from this perspective, would warrant the experience of the reactive attitudes (in particular blame and resentment) on your part.

The claim that moral obligation is best understood as what would warrant the experience of the reactive attitudes is a variation on Strawson's claim in his classic article 'Freedom and Resentment' (Strawson, 1974). In 'Freedom and Resentment', Strawson claimed that human beings are disposed to experience negative reactive attitudes towards other agents who have wronged them as long as the wrongdoer is a "psychologically normally developed" agent and is acting voluntarily and in full knowledge. On a conceptual interpretation of Strawson's claims, to hold someone responsible implies being disposed to experience the reactive attitudes towards that person. Darwall has slightly revised Strawson's claim by specifying that "what we are morally obligated to do is, as a conceptual matter....what would warrant blame....if done without adequate excuse" (Darwall, 2010, 221). Darwall takes someone to be responsible when she is justifiably held accountable for her conduct and thus rightly subjected to the reactive attitudes of the victim.

2 The concept of a range property was introduced by Rawls and stipulates that everyone who possesses a property within the range is equally within the range (Rawls, 1999, 443). In other words, nobody is a more competent member of the moral community; once you are a member of the moral community, you are an equal member of the moral community and nothing more needs to be said about your level of competence. 
If the content of a moral obligation is determined by what would warrant the experience of the reactive attitudes, one might ask: how is second-personal competence related to the warranted experience of reactive attitudes? On this, Darwall follows once again the stance taken by Strawson. On Strawson's view, experiencing the reactive attitudes presupposes that the addressee of your reactive attitudes has the capacity to understand what is demanded from her and act on it (Darwall, 2006, 76). In other words, when you experience the reactive attitudes towards another agent, your experience of the reactive attitudes presupposes the second-personal competence of the individual towards whom you experience the reactive attitudes. I have now discussed what the reactive attitudes imply in terms of holding others responsible for their actions. But I haven't yet said anything about what reactive attitudes do. On Darwall's view, reactive attitudes issue demands to the person they address. On that point, he follows Strawson who also claimed that "... reactive attitudes implicitly address demands. They involve an expectation of and demand for certain conduct from one another" (Strawson, 1968, 85). Viewing reactive attitudes as a form of demand is not unique to Darwall or Strawson. Jay Wallace takes the reactive attitudes to "reflect the psychological attitude of demanding" and Gary Watson takes them to be "incipient forms of communication which express demands" (Wallace, 1994; Watson, 2005).

These demands that we make on one another when we enter the second-person standpoint need not be explicit, they can also be implicit, as some reactive attitudes can be unexpressed feelings like resentment and guilt (Darwall, 2006, 3). Moral accountability is second-personal to the extent that it presupposes the victim having the authority to make a demand to be treated otherwise and the reactive attitudes express this implicit demand. Moreover, Darwall specifies what the reactive attitudes demand; he argues that the reactive attitudes actually demand the reestablishment of reciprocally recognizing respect (Darwall, 2006, 60). This demandmaking feature of the reactive attitudes will be an important premiss for two of the arguments examined critically below.

\section{Disdain and Contempt according to the Second-Person Standpoint}

\subsection{Disdain and Contempt}

To begin with, let me say a bit more about the attitudes of disdain and contempt. Darwall speaks of disdain, but I take these two attitudes to be closely related and, for the purpose of this essay, I will not distinguish sharply between the two. ${ }^{3}$ According to the Oxford English Dictionary, contempt derives from the old French contemner, which means to disdain, so the two concepts are etymologically very close. Let me thus focus here mostly on the notion of contempt which has been the object of much more in depth analysis. The first thing that ought to be pointed out about contempt is that it is "characterized as a way of negatively and comparatively regarding someone who is presented as falling below the contemnor's personal baseline." (Bell, 2013). In other words, the person who is in position of holding someone else in contempt expresses a belief in her own relative superiority. Moreover, this superiority is affirmed when the person held in contempt has failed to meet an interpersonal standard crucial in the contemnor's value system (Bell, 2013). This interpersonal standard constitutes the contemnor's personal baseline. When someone stoops below this personal baseline, he/she will be held in contempt by the agent in question.

Another important feature of contempt is that it is a globalist attitude, that is an attitude which takes whole persons as its object (Bell, 2013) instead of taking an action as its object (Mason, 2003, Bell, 2005). Although this characteristic of contempt has been challenged (Abramson 2009, Ben Ze'ev, 2001), I will assume here that contempt is a globalist attitude. It would be, of course, easier to make a case in favour of a reappraisal of contempt if it were not a globalist attitude. But I don't want the defence of the attitude of contempt I will put forward here to be 1) too easy and 2) contingent on it not being a globalist attitude. Moreover, one of the arguments I examine assumes also that contempt is a globalist attitude (namely the argument proposed by Darwall that contempt treats the wrongdoer disrespectfully).

\footnotetext{
${ }^{3}$ Scorn might be another very closely connected concept.
} 
Another noteworthy feature of disdain and contempt is that their negative evaluation is coupled with an affective as well as a behavioural withdrawal from and avoidance of the object of contempt and disdain (Bell, 2005 , 84). This psychological withdrawal is key in differentiating sharply disdain and contempt from other emotional attitudes that negatively evaluate but keep engaging emotionally and behaviourally with the negatively valued individual, such as anger and resentment. When one holds someone in contempt, the object of our contempt doesn't elicit any strong emotional reaction any more and his/her company is no longer sought. In other words, avoidance and withdrawal are essential features of the attitudes of disdain and contempt (Abramson, 2009, 202). These features will be crucial in my argument in this paper. I will argue that these features are not necessarily problematic and that, instead, we should take them to be crucial elements in our prerogative as moral agents to decide which interpersonal relations we want to have and which we want to let go.

\subsection{Which Normative Implications for Disdain could be drawn from the Second-Person Standpoint?}

In section 3, we have established that, on Darwall's view as developed in the SPS, the experience of the reactive attitudes is a form of demand for whatever it is that would re-establish reciprocal recognition respect, that is, the respect owed to all individuals qua morally free agents. This clearly implies that reactive attitudes are valuable and ought not to be abandoned. Disdain (or contempt) however is typically an attitude of disengagement which is incompatible with experiencing the reactive attitudes. If reactive attitudes involve a demand for respect, the absence of reactive attitudes and the substitution of attitudes of disengagement such as disdain and contempt might appear to be disvaluable. So the disvalue of the attitudes of disdain and contempt seem to be a normative implication of the Second-Person Standpoint. There are three different reasons why giving up on the reactive attitudes to endorse the attitudes of contempt and disdain might be disvaluable: it might be seen as amounting to lacking self-respect, disrespecting the object of contempt or undermining the claim that a moral obligation has been violated. Let me say a few words about each of these in turn before I develop responses to these arguments in section 6 .

\section{A. Self-respect}

One reason for taking disdain and contempt to be disvaluable is that the experience of disdain or contempt would amount to giving up on demanding to be treated respectfully. Recall that, if one takes disdain, as Darwall does, to be contrasted with the reactive attitudes, the experience of disdain replaces the experience of the reactive attitudes. ${ }^{4}$ Recall also that, on Darwall's account, the reactive attitudes are a demand for respect. If disdain is taken to replace the experience of reactive attitudes, then it is problematic in so far as no reactive attitude is experienced and no demand to be treated respectfully is made. So if a victim resorts to disdain instead of the reactive attitudes, she is giving up on her demand to be treated respectfully. In support of this view, consider Jeffrie Murphy's claim that:

"not to have what Peter Strawson calls the reactive attitude of resentment when our rights are violated is to convey-emotionally-either that we do not think we have rights or that we do not take our rights very seriously." (Murphy, 1982, 17)

According to Murphy, the absence of reactive attitudes in the face of a wrongdoing implies that the victim is not taking her rights seriously and possibly showing lack of self-respect. Murphy is here concerned with the specific reactive attitude of resentment, but one can safely assume that it can be extended to other reactive attitudes, such as anger. Moreover, this view seems to be a normative implication of adopting Strawson's view

\footnotetext{
${ }^{4}$ I will be assuming here and throughout that if one feels disdain or contempt towards some wrongdoer, that attitude normally leaves no space to also feel anger or resentment towards the same person, at least not for the same wrongdoing.
} 
on the reactive attitudes. I won't discuss specifically this argument but one of the responses I give below (see section 6.1) can be used to briefly address this concern and reject this argument.

\section{B. Lacking Respect towards Wrongdoers}

Darwall also argues explicitly that disdain is disvaluable (and seems to suggest that this is a normative implication of the SPS). However, he does so for another reason. The problem, according to him, is not that the disdaining party would show a lack of self-respect towards himself by giving up the reactive attitudes, but that he would be lacking respect towards the disdained party. Similarly, Kant claimed that we had a duty to avoid contempt, because it is incompatible with respect (Kant, 1991, 255). In other words, although Darwall also claims that a normative implication of the SPS is that disdain is disvaluable, his account of why and how it is so is wholly different from the one mentioned above.

This view follows from the account presented by Darwall. I mentioned above that a distinctive feature of disdain (and contempt) is its being an attitude that shows behavioural disengagement. This behavioural disengagement can be taken to show that we are not expecting a change for the better on the part of the wrongdoer. If we take the Strawsonian account seriously, not expecting a change for the better amounts to giving up on the wrongdoer as a member of our community of moral equals (Hill, 2000). Given this understanding of these attitudes, they might indeed seem problematic on the second-personal account of morality developed in the SPS.

When Darwall describes the difference between the experience of the reactive attitudes and the experience of disdain, the worry he mainly points out with the attitude of disdain is that it fails to treat the wrongdoer as still belonging to the moral community of equals. According to him, unlike the experience of the reactive attitudes, experiencing disdain writes off the wrong-doer; it implies that one stops engaging with him/her. Disdain presupposes no authority on the part of its object (Darwall, 2006, 77). Unlike the experience of reactive attitudes, disdain doesn't attribute to the disdained person the capacity to act on the second-personal reason which is connected to the authoritative demand (Darwall, 2006, 77). In contrast, experiencing the reactive attitudes shows that one presupposes that the object of our reactive attitudes has the capacity to act on the second-personal reasons that he/she has violated: "When we respond reactively to someone who fails to respect a moral demand, we attribute to her the capacity to act on the distinctive kind of reason, secondpersonal reason, that is connected to the authoritative demand." (Darwall, 2006, 77). When we experience the reactive attitudes, we are not merely demanding to be treated in a different way but we presuppose that the individual in question is capable of recognising this demand and of recognising our authority for pressing that demand (Darwall, 2006, 77).

As an illustration of his stance on disdain, Darwall brings up the particular example of two ice skating performers, Barbara Fusar Poli and Maurizio Margaglio. In one particular performance, Maurizio Margaglio slightly dropped Barbara Fusar Poli during their performance, causing her to give him at the end of the performance a very expressive stare that she addressed to him as a way of conveying her disappointment at his mistake and her asking him to account for it. Darwall contrasts this expressive stare with another kind of possible facial expression that could be adopted in similar circumstances:rollings one's eyes. Rolling one's eyes is, from Darwall's point of view, a fairly straightforward expression of disdain. It expresses having given up on the person being able to do better as it were and not taking them as having moral freedom. I will put this claim into question below by arguing first that the ideal character of Darwall's account blocks it from having such a normative implication (see section 6.1) and second that disdain (and contempt) far from showing lack of respect, presupposes respect (see section 6.2).

\section{Undermining the Moral Wrongness of an Action}


Finally, a more radical move would point out that not experiencing the reactive attitudes would undermine the very claim that a wrong has been committed. Recall that, according to Darwall, what we are morally obligated to do is, as a conceptual matter, what we are warrantedly held responsible for doing, what would warrant blame and be culpable if done without adequate excuse (Darwall, 2010, 221). This could lead us to believe that the absence of reactive attitudes and the adoption instead of an attitude of disengagement, such as disdain and contempt would undermine the claim that a wrong has been committed. However, I will argue that the fact that a wrongdoing warrants blame will not be affected by whether or not the reactive attitudes are experienced in a particular actual case. Whether or not a wrongdoing warrants blame will only be affected by whether or not it would warrant the experience of the reactive attitudes by ideal members of the moral community. I will return to this later (see section 6.1).

\section{Two Objections}

\subsection{Can the SPS have Normative Implications?}

But before I attempt to reject the views mentioned above, let me consider straightaway a possible objection to the claim that the SPS might have any normative implication. To say that the SPS has a normative implication is to say that it entails a claim about what is valuable and disvaluable. However, the SPS is a metaethical account. Why shall I assume that one can derive substantive normative claims from the SPS? After all, it is generally assumed that one can't derive substantive normative ethics claims from meta-ethical ones.

To that I shall respond that, although the SPS is mostly concerned with meta-ethical issues, Darwall himself recognises that the arguments developed within the book might have normative implications for the content of our moral obligations:

"But what specific demands does this shared basic authority legitimate? What specifically can we reasonably expect of one another? This is obviously a normative ethical question rather than a fundamental metaethical issue of the kind on which SPS takes an explicit stand... But while SPS is largely silent on specific normative questions concerning the content of our moral obligations, I believe that its arguments have substantial normative ethical implications nonetheless." (Darwall, 2010, 225-226).

If Darwall himself claims that one can take the SPS to have normative implications, then we can at least not reject as obviously wrong-headed attempts to derive normative implications from the SPS. Moreover, throughout my argument below, I will show how such normative implications seem quite naturally to follow from the SPS.

There is much more to say about the difficulties to derive a normative implication from a meta-ethical account but I won't be discussing this here. However, in one of my responses, I will point out that the SPS can't have normative implications for the question of the value of the actual experience of disdain, because of its ideal character. And I will be discussing the validity of only one such ethical implication, namely, that the replacement of reactive attitudes by an attitude of disengagement, such as disdain, is necessarily morally disvaluable.

\subsection{Disdain and Contempt: Distinctive Reactive Attitudes?}

But all this presupposes that disdain is not one of the reactive attitudes. But if one challenges this claim, some of the arguments presented above might not hold. Consider the argument to the effect that disdain fails to treat the wrongdoers with respect. Let us schematically summarise one of the arguments presented above in the following way: 
1. The reactive attitudes are required if wrongdoers are to be held accountable.

2. If one feels disdain towards a wrongdoer, one (normally) cannot also feel reactive attitudes towards that wrongdoer.

3. Disdain fails to hold wrongdoers accountable, and fails thus to respect wrongdoers as free moral agents.

Therefore

4. Disdain is morally disvaluable or inappropriate.

This argument could be resisted if we rejected premise (2), and showed that disdain is in fact itself a reactive attitude. Michelle Mason has argued that contempt is a reactive attitude, as it is "a reaction to another's expressing towards us or those of concern to us some quality of will" (Mason, 2003, 251). But I believe that more can be said in favour of disdain than merely stating that it is also a reactive attitude. Note however that some of the arguments I will present below could be interpreted to also support the claim that disdain is a kind of reactive attitude.

I don't think however that the argument needs to turn on whether or not disdain and contempt are reactive attitudes (premise 2) but rather on the more important question of whether or not disdain is compatible with holding the object of disdain responsible (premise 3). If premise 3 can be held independently from the reactive attitudes account, the argument could be formulated without premises 1 and 2 . The objection might thus not invalidate a similar argument provided that premise 2 is not used.

\section{Two Answers}

Let me now defend the view that disdain is not necessarily morally disvaluable or problematic. For that purpose, I will suggest two different responses to the arguments presented above to the effect that disdain is disvaluable. The first one will point out that the normative implication that disdain is disvaluable only follows from the account if we are unclear about the nature of the claims made. The claims made pertain to the disposition that ideal members would have and the account is definitely ideal. The experience of the reactive attitudes in itself doesn't ground any moral obligation, as the moral obligation is independently grounded on the disposition that hypothetical members of the moral community would have. The actual experience or absence of reactive attitudes has thus no immediate implication for moral obligation or responsibility. I point out that the ideal character of the account also undermines the validity of the argument based on self-respect.

The second answer is that, contrary to the claims made by Darwall, experiencing disdain presupposes that the victim holds the object of disdain responsible and accountable for her character traits as instantiated by her behaviour. Without the presupposition of accountability, no disdain would be experienced by the victim towards the wrong-doer. In order to defend this position, I will introduce a distinction between normative and empirical expectation towards the wrong-doer.

\subsection{Actual vs Ideal}

The first answer would be to point out that the hypothesis presupposes that actually experienced reactive attitudes are what matters and what ground moral obligation. But this could be denied and this would block Darwall's account from having the implication that experiencing disdain would undermine the very claim that a wrong has been done and that a moral obligation was violated. (As I will point out, this section will also clarify why I think that the ideal character of Darwall's account also undermine the validity of the other arguments.) Recall 
that I have assumed that experiencing disdain leaves no space to experience the reactive attitudes. If actually experienced reactive attitudes are required to ground moral obligation, experiencing disdain would undermine the claim that a wrong has been done and that a moral obligation has been violated. It would thus be morally problematic to experience disdain, as it would imply that no moral obligation has been violated.

Many critics have argued that the SPS should not remain vague on this issue, as taking the view that actually experienced reactive attitudes ground moral obligation would be very problematic. One such objection is articulated for instance by Jay Wallace: he argues that it is counter-intuitive to claim that I wronged you only when you raised a demand not to have your foot stepped upon and not beforehand, that is, when your foot is being stepped upon in the first place:

"this has puzzling consequences if we take seriously the idea that it is the addressing of a claim or demand that is the source of distinctively second-personal reasons. The claim or demand that is at issue in this case is the victim's protest, which we should understand as creating a reason for you to desist, in virtue of the victim's authority to make demands of precisely this nature. ...this cannot be right however. Surely we want to say that you have an agent-relative reason not to step on someone's gouty toe that is (to some degree) prior to and independent of any complaint that might be issued after the toe has actually been stepped on." (Wallace, 2007, 26).

In other words, Wallace argues that the SPS hinges on making moral obligation depends on the actual response of individuals in interaction with each other (Wallace, 2007, 27). ${ }^{5}$ There are different ways in which it might be objected that the second-personal standpoint seems to make moral obligation depends on the actual response of individuals. Appropriately, there are two different responses that Darwall gives to these different ways of understanding this objection.

First, one way of understanding this objection is to see it as stating that actual individuals who have generally second-personal competence fail in this particular instance to experience the reactive attitudes. We could imagine cases in which someone is temporarily depressed or is affected by something else, to the extent that the particular wrong in question doesn't really affect her. It is particularly easy to conceive of such a case if we consider the foot stepping case. The sharp pain resulting from the foot stepping might just not elicit any reactive attitudes in a person otherwise troubled by psychological grief. It seems right to say, following Wallace, that it would be odd to conclude from the absence of reactive attitudes experienced by the victim to the claim that there was no moral obligation not to wrong the victim in the first place.

However, Darwall replies to this objection by pointing out that his account assumes that demands are addressed not only when they are articulated but whenever there is a disposition to respond to certain norm violations with the reactive attitudes (Darwall, 2007, 65). What Darwall has in mind is thus the demand that is implicit in the disposition to experience the reactive attitudes. There is thus no need for the individual in question to actually experience the reactive attitudes for her to be wronged. It suffices that she has the disposition to experience the reactive attitudes in this case. The fact that the expression of this disposition is blocked by other factors doesn't undermine the existence of this disposition.

Second, the objection could take another form, and be further pressed against Darwall's account, as not every being (human or non-human) has even this general disposition to experience the reactive attitudes when wronged. The objection would then point to the counterintuitive nature of claiming that these beings can't be wronged (or held accountable) because they generally lack such a disposition. Recall that, in Darwall's view, lacking such a disposition amounts to lacking second-personal competence. This seems to imply in particular that autistic individuals and psychopaths which Darwall take to lack second-personal competence, can't be wronged or held accountable, which seems counter-intuitive. When confronted with this version of the

\footnotetext{
${ }^{5}$ Michael Smith and Jada Strabbing voice a similar worry when they wonder whether the reason not to wrong the victim existed all along or whether it is created by the demand (Smith and Strabbing, 2010, 239, ftnte 2).
} 
objection, it is not clear to me what Darwall's reply is, as he seems to resort, in different passages, to two very different kinds of response.

Darwall seems purposedly to leave it open whether or not one could be accountable without having secondpersonal competence. He doesn't commit himself to the view that second-personal competence is necessary for moral accountability but only to the view that second-personal competence is sufficient for moral accountability. This leaves entirely open the possibility that those who lack second-personal competence could nevertheless be held accountable. However, this accountability would be grounded elsewhere, not in the second-personal standpoint.

But in many passages, Darwall invokes another kind of reply: it is not the disposition to experience the reactive attitudes, as entrenched in actual individuals, but rather the disposition that ideal members of the moral community would have which ground moral obligations. He says so explicitly in his reply to Wallace:

"but the moral community as I understand it is not any actual community composed of actual human beings. It is like Kant's idea of a realm of ends, a regulative ideal that we employ to make sense of our ethical thought and practice. ...We might therefore understand the moral community as being prone to the reactive attitudes in a contractualist way, for example, taking it that moral demands are in force if no one could reasonably reject principles that would warrant them..." (Darwall, 2007, 65)

In this passage, it is made clear that what really grounds the moral demand is the disposition that hypothetical members of the moral community would have towards the reactive attitudes. But if the notion of demand implicit in the reactive attitudes we experience is crucial to determine moral obligation, it matters a great deal whether what grounds this demand is the disposition to the reactive attitudes that ideal members of the moral community would have or the experience of these reactive attitudes by actual individuals. If the demand implicit that is at stake is the one that hypothetical members of the moral community would be disposed to have, whether or not one individual experiences the reactive attitudes (or is disposed or not to experience the reactive attitudes) is not going to undermine the moral obligation. What we as actual individuals end up experiencing will not have an impact on the existence of a demand that is implicit in the disposition that hypothetical members of the moral community would have. But if that is the case, this cannot be a ground for claiming that the experience of disdain is morally problematic, as not experiencing the reactive attitudes is irrelevant to whether or not a moral obligation has been violated.

Let me clarify the importance of this point. If, on Darwall's view, wrongness and accountability are grounded in the actual experience of reactive attitudes, then the absence of the reactive attitudes (because one feels disdain) could actually mean that the act isn't wrong, the victim hasn't been wronged, there was no obligation to act otherwise, etc. But if this grounding role of the reactive attitudes relates to an ideal community, this worry dissolves and the experience of disdain doesn't undermine any of these claims. Bringing up the hypothetical members of the moral community has thus a big impact on what kind of implications the second-personal account of morality presented in the SPS can have on disdain.

Moreover, this point also undermines the two alternative arguments briefly sketched in section 4.2. If what matters is what the members of the ideal community would be disposed to experience, the actual experience of disdain towards a wrongdoer can't have the implication that the victim lacks self-respect or that the victim disrespects the wrongdoer. Recall that what actual individuals end up experiencing will not have an impact on the disposition that hypothetical members of the moral community would have. Once again, only what ideal members of the moral community would be disposed to experience will have normative implications. So this response undermines also the validity of the argument based on self-respect and the validity of the argument based on respecting wrongdoers mentioned above, as they both claimed that the SPS would have normative implications for the value of the actual experience of disdain by individuals.

Let me add that this is a puzzling move for the general account defended in the SPS. After all, the whole point of taking a second-personal perspective is to stay grounded in actual personal interactions and what 
they mean to each of us. The second-personal standpoint is usually invoked to avoid taking a third-person standpoint where moral obligations might be defined in a way that seems contrary to our day-to-day intuitions. Similarly, reactive attitudes are usually invoked in order to emphasize that what matters is what kind of emotions we actually have with respect to each other. The role of the reactive attitudes in Strawson for instance, is definitely to ground moral responsibility in our actual emotions and the intuitions that actually prevail in our interactions with each other. It is thus puzzling to take reactive attitudes to have such a crucial role in determining our moral obligations but then qualify them as those reactive attitudes hypothetical members of the moral community would be disposed to experience. Hypothetical members of the moral community are omniscient and thereby epistemically at least occupying the third-personal standpoint. If really what is determining our moral obligation is the kind of reactive attitudes that the members of Kant's realm of ends would experience, this seems to lie far away from what is usually taken to be the prerogative of the second-person standpoint and the reactive attitudes: our actual interactions with each other.

Now this is a general issue that the account defended in the SPS needs to address, but, as I argued above, it also has implications for the much narrower question that interests me here. Not experiencing the reactive attitudes and experiencing disdain (or contempt) in their place cannot be said to be morally disvaluable, I suggest, because the actual experience of disdain cannot affect the disposition that hypothetical members of the moral community would have. The absence of reactive attitudes and the experience of disdain do not thus undermine the claim that the object of disdain has behaved in a blameworthy fashion (and similarly the experience of disdain doesn't show lack of self-respect on the part of the victim or disrespect the object of disdain).

Although the actual experience of disdain might not have direct normative implications, Darwall could argue that individuals ought nevertheless to strive to have the same attitudes that the ideal members of the moral community would have. In response to that, the only thing I will have space to argue for here is that, even if hypothetical members of the ideal moral community should feel resentment rather than disdain towards wrongdoers, it remains an open question whether actual victims should feel this way. This presumably revolves on whether disdain fails to respect the moral freedom of the wrongdoers. So let me now turn to this question.

\subsection{Disdain Presupposes Responsibility}

On Darwall's account, the key worry about disdain is that this attitude is incompatible with holding the object of disdain to be morally free and thus thereby lacking respect towards him/her. In this section, I will focus on putting into question that claim.

I will argue against the claim that disdain necessarily denies that the object of disdain is capable of secondpersonal competence. On the contrary, I will argue that, in the same way that reactive attitudes presuppose the second-personal competence of their target, disdain similarly presupposes such second-personal competence. Note that I will remain uncommitted here as to whether or not this indicates that disdain is also best seen as a reactive attitude. What matters for a defence of disdain and contempt as morally justified attitudes is that they are not incompatible with holding wrongdoers responsible and that they are thus not necessarily lacking respect towards wrongdoers.

Before I introduce my own arguments, I would like to briefly consider the arguments put forward by Kate Abramson in her attempt to rescue contempt from the charge that experiencing contempt towards someone is incompatible with holding this person responsible (and hence treating her with respect). She introduces a distinction between localised and global forms of contempt. Whereas localised forms of contempt are restricted to a specific sphere of interpersonal relation, global forms of contempt encompass the individual whole in its evaluation. She argues that only globalised contempt might be difficult to reconcile with 
respecting and holding the wrongdoer responsible. In other words, as long as the contempt experienced towards someone is localised, this is compatible with holding this person accountable.

She claims that localised contempt and its behavioural tell-tale sign of avoidance makes sense as a way of holding people accountable for not being reliable in some particular sphere of interpersonal relations (Abramson, 2009, 210). I agree with her that contempt results from holding individuals responsible for their actions. As I elaborate below, a negative evaluation of an individual is only possible if we take that individual to be morally free. However, I don't think that the localised vs globalised distinction helps here. To begin with, some aspects of character in one sphere of interpersonal relation might have implications for another sphere of interpersonal relation. If someone exhibits a very selfish character while interacting with his colleagues, it doesn't necessarily imply that the individual in question will be selfish in every personal interaction he has. In practice, however, a character trait is rarely restricted to one area of interaction. But more generally, I believe that, even if an individual commits wrongdoings in various spheres of interpersonal relations, and contempt of a greater scope is warranted towards her, one could still hold her responsible for her behaviour. As I will argue below, contempt presupposes responsibility rather than exclude it.

Let me now explain why I believe that disdain doesn't entail lacking respect towards the disdained party. Recall what was said above in this paper about the way Darwall conceives of second-personal competence. Second-personal competence is the ability to comply with norms for the right reasons, that is, because one recognises that others have authority to make claims upon us. It was also described as the ability to recognize moral reasons. But if second-personal competence is the ability to recognize moral reasons then I don't see how disdain would not, like resentment, presuppose that its object has this ability. Disdain can only be experienced towards those who we take to be responsible and anyone who is taken to be responsible has second-personal competence.

To show this, take the example of a schizophrenic person who, in the midst of a paranoid hallucination, kills someone. Assuming that we are convinced that he was having a hallucination, it would be indeed hard to experience resentment towards the schizophrene. But it would be as unlikely that we would experience disdain towards him. This is so because we don't experience disdain or the reactive attitudes towards those who can't do better. The same could be said about resenting an autistic individual for not being moved enough by empathic feelings. It would be inappropriate for me to experience either the reactive attitudes or disdain towards her, because of her inability to experience empathic feelings. ${ }^{6}$ In other words, we can appropriately feel disdain only towards those we hold morally responsible, and those who can be held responsible have second-personal competence. As Michelle Mason has expressed this thought eloquently: "Regarding another with contempt does not thereby objectify another person; rather, it is regarding him as beneath contempt that signals we have exiled him from the moral community with us." (Mason, 2003, 263).

Another way to argue for the claim that disdain doesn't fail to show respect to the blameworthy individual and hold her accountable would be to invoke Darwall's own distinction between recognition and appraisal respect (Darwall, 1977. Appraisal respect is close to the concept of esteem. It is the kind of respect I have towards individuals I admire for something they do or a character trait they exhibit. For instance, it is the kind of respect I will experience towards people I admire for their intelligence, their courage, ability to reach some difficult yoga poses or work achievements. Appraisal respect is displayed by "persons or features which are held to manifest their excellence as persons or as engaged in some specific pursuit" (Darwall, 1977, 38). Appraisal respect is not owed to all persons; it is owed to those who deserve it.

By contrast, recognition respect is the respect that one owes to all persons. It implies that "they are entitled to have other persons take seriously and weigh appropriately the fact that they are persons in deliberating about

\footnotetext{
${ }^{6}$ I think the case of the psychopath might be different, but I believe that the psychopath case is more controversial than these other cases. One might take the psychopath responsible and thus accountable for what he does. My intuitions on the case of the psychopathic case is that we could both experience disdain or the reactive attitudes towards him. But we can put aside this case for now.
} 
what to do." (Darwall, 1977, 38). If some facts or features are appropriate objects of recognition respect, this entails that "inappropriate consideration or weighing of that fact or feature would result in behaviour that is morally wrong. To respect something is thus to regard it as requiring restrictions on the moral acceptability of actions connected with it." (Darwall, 1977, 40). Moreover, this restriction would arise not incidentally but because of the feature or fact in question. In other words, it is because they are free moral agents that our actions towards them are limited by the boundaries of morality. A final distinghuishing feature between the two forms of respect is that whereas recognition respect (like second-personal competence) is a range property supervening on some basic agential capacities, appraisal respect is a scalar property.

But if one uses this distinction the charge against disdain loses its grip. Recall that whereas appraisal respect is the respect I experience towards an individual for some achievement, recognition respect, according to Darwall, is the respect I owe to all individuals. But if recognition respect is the respect I owe to all individuals, when I experience disdain towards a person, it is thus not her recognition respect which is at stake. I must also respect (in the recognition respect sense) those I feel contempt or disdain towards. When I experience disdain, I rather indicate very low appraisal respect. I experience disdain towards someone who has behaved less than examplarily towards others, it doesn't mean that there are no moral restriction as to how to treat this person. I still owe her recognition respect. Moreover, there is nothing problematic about experiencing low appraisal respect towards some individuals, as it is after all the whole point of appraisal respect to regard individuals differently according to their merit. Low appraisal respect needs to be experienced towards those individuals who have stooped below a certain standard. Moral agents who reflect on what values there are adopt such standards. If they were not to react to the crossing of such standards by endorsing the attitude of contempt, one might question their real commitment to the values they have. As Macalester Bell writes: "There is a conceptual connection between valuing and being disposed to a range of hard feelings when what one values is threatened. If you claim to value something but you aren't disposed to feel any negative emotions when what you claim to value is in jeopardy, there is reason to doubt that you actually value what you claim to value.” (Bell, 2013, p.161).

But an objector might press on, this seems to make light of the fact that when I experience contempt towards someone, I stop expecting better from her. Surely ceasing to expect better from someone implies that I cease to treat as a free moral agent? I don't think so. I believe that this only indicates to us that a distinction ought to be drawn between giving up expecting better from this person on a normative sense, thereby assuming that the person is no longer part of our moral community (i.e. the person cannot behave morally at all, has no second-personal competence) and giving up demanding and expecting better from this person in an empirical sense.

What is crucial here is the distinction between normative expectations and empirical expectations. Disdain might be compatible with holding certain normative expectations of the individual but not with keeping (implausible) empirical expectation that the individual will in fact do better. I have a normative expectation that individuals should, and therefore can, do better, and this would apply to every individual that I take to be, in Darwall's own terminology, a member of the community of moral equals. Every member of that community is accountable and can be held responsible for their actions. I would stop having the normative expectation that these individuals can do better only if I judge them to be outside our moral community. However, I can still legitimately lower my empirical expectations of some individuals, when these expectations need to be adapted on the basis of the evidence provided by their past behaviour.

Let me take the example of Berlusconi. Let us say that I experience disdain towards Berlusconi. This disdain could result from an examination of his personal or political actions. It doesn't matter for the particular purpose here why I experience disdain towards him. This disdain, in my opinion is justified, because I believe he could behave better, that is, that he is able to do so. ${ }^{7}$ If I believed he could not behave better, say he was rather subjected to some strong compulsion that led him to take some political course or to behave in a

${ }^{7}$ Of course, I might be wrong in thinking so, but if I believed otherwise, that is, that Berlusconi was not able to behave better, I would not experience disdain towards him. 
certain way privately, then it would be strange for me to experience disdain towards him. By experiencing disdain, I am not saying however that I stop expecting him normatively to behave better. My normative expectation towards him is unchanged-I still take him to have full moral agency and hold him accountable for his actions. However, I don't expect him empirically to behave better. In fact, I would be a fool if I did. I would be lacking some fundamental common sense if I was surprised to hear that he lacked political judgment or that he behaved viciously in his private life.

In other words, I don't take disdain to be shutting off the wrong-doer from the moral community. Disdain however, might lead us to shut the disdained person off from those we trust, love, esteem or even interact with. But this is all right, as trust love and esteem are emotions that are better felt towards those who deserve them. More controversially, I believe that disdain is actually the appropriate attitude to have towards those people, like Berlusconi, whom we (empirically) expect to continue to misbehave and violate basic rules of moral conduct.

In fact, there are cases where feeling resentment towards a wrongdoer would appear naïve. To be sure, it is always permissible for the victim to experience the reactive attitudes with respect to a wrongdoing. However, experiencing resentment would be psychologically sound only if the wrongdoing comes as a surprise. But if the probability that, say, a repeat offender will commit a wrongdoing is very high, then feeling resentment towards this wrongdoer might be inappropriate on empirical grounds. First, it seems to be epistemically defective to still expect better behaviour in the face of strong counter evidence. Second, and more practically, it would just be emotionally exhausting to do so continuously. So although it is permissible to experience the reactive attitudes, there might be practical reasons in favour of substituting disdain to resentment in certain cases.

Let me give you an illustration of such a case. This case might involve the absence of resentment rather than straightforward disdain, but it is similar enough, to the extent that it presupposes an empirical expectation that the person would not do better. Some time ago, Obama was reported by the media to have said that he "couldn't bother getting angry" about Netanyahu's agreeing to new settlements on the West Bank. Of course, one could read this "couldn't bother getting angry" itself as an expression of resentment and anger. But if we take the exclamation to be a more honest reflection of Obama's actual state of mind, then this would exactly illustrate the point made above. The empirical expectation that Netanyahu would make such a decision was very high, and to become angry at the news would have indicated naivety. "Bothering getting angry" in this case would have indicated that Obama had failed to take into account evidence from the past to draw conclusion about the likelihood of a certain behavior in the future. Obama's empirical expections have adjusted to what is likely for Netanyahu to do and achieve, but that doesn't mean that his normative expectations have adjusted. Obama still think that Netanyahu should have prevented the building of new settlements on the West Bank and this remains his normative expectations towards Netanyahu.

\section{Conclusion}

The second-personal account of morality developed by Darwall in The Second-Person Standpoint seems to imply that the attitudes of disdain and contempt are morally problematic and disvaluable. Darwall indeed explicitly argues that disdain is problematic to the extent that it doesn't treat its object as morally free, that is, as able to do better. This view seems to prima facie follow from the second-personal account developed in the SPS.

A fundamental claim of the account is that the reactive attitudes issue a demand to be treated with respect. But if that is the case, the withdrawal of the traditional reactive attitudes of resentment and anger and their replacement by an attitude of disregard (whether contempt or disdain) can appear to give up on making that demand. Giving up on the demand to be treated with respect has been taken to be problematic for various reasons: it might show lack of self-respect (Murphy, 1982), it might fail to treat the wrongdoer as morally free and belonging to our community of moral equals (Darwall, 2006, Hill, 2000), it might fail to show the respect 
we owe to every individual (Kant, 1991) or it might undermine the very claim that a moral obligation has been violated (Wallace, 2007).

In this paper, I have suggested two possible ways to reject the claim that disdain is necessarily disvaluable for any of these reasons. First, I have argued that one cannot derive from the account defended in the SPS these normative implications about disdain, as the account grounds moral obligation and moral responsibility on the dispositions of hypothetical members of the moral community. In Darwall's view, the second-person standpoint is constituted by the perspective of hypothetical members of the moral community, and moral obligation is constituted by what would warrant their reactive attitudes. To that extent, the actual attitudes of individuals are irrelevant. In other words, the SPS is pitched at the wrong level to have the direct normative implications about disdain that have been thought to follow from it.

Second, I have argued that, even if we granted that the SPS could have such implications, and contrary to what is argued in the SPS, disdain doesn't fail to presuppose the ability of its object to change, or fail to treat its object with respect. This becomes clear when one considers the matter in terms of Darwall's distinction between recognition and appraisal respect as well as in light of the distinction I have introduced between empirical expectation and normative expectations. Disdain can thus be seen as having two main virtues. First, it is an attitude that is fact-sensitive, it allows agents to adjust their empirical expectations to others' wrongdoings. Second, it fulfills the important function of restricting the number of agents towards which we experience the emotionally demanding reactive attitudes when they let us down. By lowering our empirical expectation towards those we experience disdain towards, we save ourselves much emotional energy. 


\section{Bibliography}

Abramson, Kate 2009: “A Sentimentalist Defence of Contempt, Shame, and Disdain”. In: Peter Goldie (ed.): The Oxford Handbook of Philosophy of Emotion. Oxford: Oxford University Press, 189-213.

Bell, Macalester 2005: “A Woman’s Scorn: Towards a Feminist Defense of Contempt as a Moral Emotion”. Hypatia 20 (4), 80-93.

Bell, Macalester 2013: Hard Feelings, the Moral Psychology of Contempt, Oxford: Oxford University Press.

Ben Ze'ev, Aaron 2001: The Subtlety of Emotions, London: MIT.

Capes, Justin 2012: “Blameworthiness without Wrongdoing”. Pacific Philosophical Quarterly 93(3), 417-437.

Darwall, Stephen L. 2010: "Precis: The Second-Person Standpoint". Philosophy and Phenomenological Research 81 (1), 216-228.

Darwall, Stephen L. 2007: "Reply to Korsgaard, Wallace and Watson”. Ethics 118(1), 52-69.

Darwall, Stephen L. 2006: The Second-Person Standpoint. Cambridge, MA: Harvard University Press.

Darwall, Stephen L. 1977: “Two Kinds of Respect”. Ethics 88 (1), 36-49.

Ekstrom, Laura W. 2000: Free Will: A Philosophical Study. Boulder, CO: Westview Press.

Fischer, John Martin and Ravizza, Mark (eds.) 1993: Perspectives on Moral Responsibility. Ithaca, NY: Cornell University Press.

Hill, Thomas 2000: Respect, Pluralism and Justice: Kantian Perspective. New York: Oxford University Press.

Hurley Elisa A. \& Macnamara, Coleen 2011: "Beyond Belief: Towards a Theory of the Reactive Attitudes". Philosophical Papers 39 (3), 373-399.

Kant, Immanuel 1991 (transl. Mary Gregor): The Metaphysics of Morals. New York: Cambridge University Press.

Mason, Michelle 2003: “Contempt as a Moral Attitude”. Ethics 113 (2), 234-272.

Murphy, Jeffrie G. 1982: "Forgiveness and Resentment". Midwest Studies in Philosophy 7, 503-516.

Nelkin, Dana 2012: Making Sense of Freedom and Responsibility. Oxford: Oxford University Press.

Rawls, John 1999: A Theory of Justice (rev. ed.). Cambridge, MA: Harvard University Press.

Smith Michael and Strabbing Jada 2010: "Moral Obligation, Accountability, and Second-Personal Reasons". Philosophy and Phenomenological Research 81 (1), 237-245.

Strawson, Peter F. 1974: Freedom and Resentment and other Essays. London: Methuen.

Strawson, Peter F. 1968: Studies in the Philosophy of Thought and Action. London: Oxford University Press.

Wallace, R. Jay 1994: Responsibility and the Moral Sentiments. Cambridge, MA: Harvard University Press.

Wallace, R. Jay 2007: “Reasons, Relations, and Commands: Reflections on Darwall”. Ethics 118(1), 24-36.

Watson, Gary 2005: "Responsibility and the Limits of Evil". In John Martin Fischer (ed.), Free Will Concepts and Challenge, London: Taylor \& Francis, 106-135. 
